\title{
A imagem entre Tarkovski e da Vinci
}

\begin{abstract}
RESUMO
A imagem entre Tarkovski e da Vinci discute o estatuto da imagem, e investiga dois modos de sua produção - o pictórico e o técnico-tecnológico - na primeira tomada do filme O Sacrifício (1986), de Tarkovski, em que o diretor filma a pintura A Adoração dos Magos (1441/42), de Leonardo da Vinci. Identifica ainda o debate sobre a imagem sob determinadas perspectivas da filosofia e da semiologia para propor um lugar propriamente comunicacional para sua análise, evidenciando a relevância de conceitos como o de meio, de referência e de sentidos. Por fim, reconhece que é no jogo sincrônico entre as imagens de Tarkovski e da Vinci que se instaura a problemática efetivamente comunicacional das imagens.
\end{abstract}

\section{PALAVRAS-CHAVE}

imagem

cinema

mediatização

\section{ABSTRACT}

This paper discusses image constitution upon investigating two modes of its production: the pictorial and the technicaltechnological. We investigate the first take of Tarkovski's The Sacrifice (1986) in which the director shoots da Vinci's Adoration of the Magi (1441/2). It also characterizes the debate about image in different philosophical and semiological perspectives in order to advance a properly communicational site for image's analysis. In this vein, we highlight the importance of concepts such as medium, reference and senses. Eventually, we propound that it is in the synchronic game between Tarkovski's and da Vinci's images that the communicational problem per se is brought about.

\section{KEY WORDS}

image

cinema

mediatization

\section{Alexandre Rocha da Silva}

Professor do Programa de Pós-Graduação em Comunicação e informação da UFRGS/RS/BR

arsrocha@gmail.com

\section{André Dornelles Pares}

Mestrando em Comunicação Social na UNISINOS/RS/BR adpares@gmail.com
Jacques Aumont, na abertura de $A$ imagem, já sentencia ser "banal falar de 'civilização das imagens'" (1990, p.14), e conclui o mesmo texto, a exemplo do que Barthes fizera na introdução dos ‘Elementos de Semiologia (1964, p.12), afirmando que a despeito da invasão de imagens, somos ainda uma civilização da linguagem verbal. Sem tal ressalva, Debord, contemporâneo a Barthes, na $18^{\mathrm{a}}$ tese da Sociedade do Espetáculo, diz que "quando o mundo real se transforma em simples imagens, as simples imagens tornam-se seres reais e motivações eficientes de um comportamento hipnótico" $(1967$, p.18). O que parece ser de certa forma retomado por Baitello Jr. ao mencionar que o crescente povoamento dos espaços urbanos pelas imagens ocorre com celeridade progressiva a partir do Renascimento e se exacerba no século XX (2005, p.88).

Em função desta inegável força que têm no nosso quotidiano a imagem, este artigo propõe discutir seu estatuto a partir de um dado encontro de imagens que faz convergir duas modalidades de representação: uma pictórica e outra técnica. Neste encontro referido, o cineasta soviético Andrei Tarkovski, na primeira tomada de seu filme $O$ Sacrifício (1986), filma parte da pintura $A$ adoração dos Magos ( 1441/42), de Leonardo da Vinci.

\section{Imagem}

No início da Metafísica, Aristóteles, como justificativa da clássica afirmação de que todo homem tem por natureza o desejo de conhecer, invoca o prazer das sensações, "e mais que todas as outras, as visuais" (1960, p.03). Flusser, por sua vez, vai definir imagens como "mediações entre homem e mundo" (2002, p.09). Com o propósito de "serem mapas do mundo", segundo o autor, elas acabam sendo "biombos". Seu argumento para isso é o de que o "homem, ao invés de se servir de imagens em função do mundo, passa a viver em função de imagens".

Principalmente por definir imagens como "superfícies que pretendem representar algo" $\mathrm{e}$ "resultado do esforço de se abstrair duas das quatro dimensões do espaço-tempo, para que se conservem apenas as dimensões do plano" (2002, p.07) a caracterização de Flusser parece, sob aspectos diferentes daqueles apresentados por Platão ${ }^{1}$, acrescentar à platônica impossibilidade de representação (principalmente imagética), um culpado extremo: "as imagens técnicas". Segundo o autor, essas imagens, "hoje onipresentes", ilustrariam a inversão, denunciada por ele e praticada pelo homem: viver em função das imagens que representariam o mundo, ao invés de valer-se delas em função dele.

$\mathrm{Na}$ Grécia de 500 antes de Cristo, ainda que a atividade de produção de imagens ficasse a cargo de quem possuía determinada "técnica" para tal, o resultado de 
seu trabalho não era certamente a mesma "imagem técnica" referida por Flusser ${ }^{2}$. No entanto, tal a argumentação platônica, os artefatos resultantes da produção de um modo imagético de representação da realidade no período grego possivelmente tinham poder semelhante sobre a sensação visual, como destacada por Aristóteles, quanto ao assinalado por Flusser às tais imagens técnicas do século XX. Ambas estariam contempladas na definição de Machado de que "a imagem, não vindo diretamente do homem, pressupõe sempre uma mediação técnica para exteriorizá-la, ela (imagem) é sempre um artifício para simular alguma coisa a que nunca podemos ter acesso direto"' (1997, p.222).

Se podemos inferir que a questão da imagem perpassa dois mil e 500 anos e chega ao século XXI suscitando ainda preocupações a respeito de seu poder sobre os âmbitos individual e social, teríamos dois pontos a considerar. O primeiro é que este modo de representação - o imagético, que se oferece à visão - guardaria sua força para além do suporte no qual é produzido, isto é, o poder da imagem não poderia ser exclusivamente reduzido às configurações dos suportes que a veiculam. O segundo é perceber no que a evolução das possibilidades de produção deste modo de representação pode ter contribuído para o poder inerente da imagem, já que o elegido por Flusser como responsáveis por vivermos em função de imagens são especificamente as imagens técnicas - ou seja, as produzidas com tecnologia para além do pictórico.

\section{Técnico x Pictórico}

Mário Carlón, em estudo que tenta encontrar distinções e aproximações entre imagens de arte e imagens de informação, questiona: "qual é o lugar dos dispositivos técnicos nesta problemática?" (1994, p.18). Mesmo não sendo esta a distinção aqui a ser procurada, a questão serve no que se refere a uma tentativa de perceber as relações entre os modos de representação imagéticos que se encontram no pictórico de da Vinci e no técnico de Tarkovski.

Segundo Carlón, a diferença básica entre essas modalidades de representação imagética é a relação com seu referente. Ambas são produzidas por analogia, mas na pictórica a relação da imagem em função do seu referente permanece a de semelhança, enquanto que na técnica (o trabalhado por Carlón é a fotografia, a partir do surgimento do daguerreótipo, por volta de 1880) a relação é a indicial (1994, p.35). Sendo "a função indicial fotográfica radicalmente mais poderosa", Carlón assinala a mudança de função (social) sofrida pela representação pictórica. Do duplo uso que tinha - artístico e informativo -, a pintura, em face o advento da fotografia, fica restrita à arte. À foto, graças a sua possibilidade de indicialidade, cabe o exercício da informação, dado seu poder de "testemunho".

Por outro lado, Machado (1997, p.227) estabelece uma hereditariedade em termos de objetivos de ambos os modos de representação imagéticos. Nesse caso, ao con- trário de Carlón, indica uma identidade de função entre os dois:

A fotografia é filha legítima da iconografia renascentista. Não apenas porque, do ponto de vista técnico, ela se faz com os recursos tecnológicos dos séculos XV e XVI (câmera obscura, perspectiva monocular e objetivas), mas sobretudo porque a sua principal função, a partir do século XIX, quando sua produção comercial se generaliza, será dar continuidade ao modelo de imagem construído no Renascimento, modelo esse marcado pela objetividade, pela reprodução mimética do visível, e pelo conceito de espaço coerente e sistemático, espaço intelectualizado, organizado em torno de um ponto de fuga.

\section{Evidentemente, o que está posto é que quando mudam os instrumentos de produção de uma imagem, as possibilidades de representação do referente consequentemente se apuram em termos de fidelidade.}

Entretanto, ao introduzir a qualidade da possibilidade de "confiança" em relação às imagens, Flusser volta a, ainda que sob outro aspecto, diferenciá-las. As possibilidades técnicas que se oferecem para a produção da fotografia - "técnica" que não se refere mais à habilidade manual do pintor no manejo do instrumento que compõe os próprios traços da imagem, mas a uma tecnologia mecânica e eletrônica - permitem ao autor afirmar que

[...] o caráter aparentemente não-simbólico, objetivo, das imagens técnicas faz com que seu observador as olhe como se fossem janelas, e não imagens. O observador confia nas imagens técnicas tanto quanto confia em seus próprios olhos (2002, p.14).

Ao empregar a "confiança" em relação às imagens técnicas, compostas por uma ligação indicial com seu referente, Flusser não quer dizer que por isso não se possa "confiar" nas imagens pictóricas, mas que inegavelmente estabelece-se uma nova relação com o modo imagético de representação. Confiar nas imagens técnicas tanto quanto confiar nos seus próprios olhos quer dizer, entre outras coisas, que não é mais necessária 
certa tradução do símbolo imagético oferecido aos olhos (como é o caso de representações imagéticas como a pintura e o desenho): o que o observador vê na imagem técnica guarda indícios (em duas dimensões) do referente - o que "elevaria" o nível de confiança em relação à função daquela imagem como testemunho (e conseqüentemente representação) da realidade.

Santaella é peremptória ao afirmar o que comumente já está estabelecido: "fotografias são consideradas mais confiáveis do que os desenhos e pinturas" (2007, p.19). É claro que faz isso como premissa para introduzir determinada confusão em termos de confiabilidade que o paradigma pós-fotográfico gera na nossa relação com a imagem $^{3}$. No que aqui interessa, entretanto, a autora esclarece a origem da fotografia como algo que "sempre se constituiu em um signo indexical", explicando que "a luz refletida do objeto fotografado altera a química do filme a ser revelado, de modo que o negativo e sua revelação sejam, de fato, um reflexo direto do mundo" (2007, p.19), para concluir, já referindo o paradigma pós-fotográfico, que "quando a crença nas aparências e na sua morfogênese é colocada em crise profunda, toda e qualquer imagem fica sob suspeita" (Santaella, 2007,p.30).

Mas se é com a "técnica" no âmbito do paradigma fotográfico (de indicialidade) que nos ocupamos na comparação com o pictórico, também podemos invocar Roland Barthes. Em A Câmara Clara (1984), o autor reitera a idéia do "isto aconteceu" como constitutiva da fotografia. Para Barthes (1984, p.13-16)

\section{[...] o que a Fotografia reproduz ao infinito só ocor- reu uma vez: ela repete mecanicamente o que nunca mais poderá repetir-se existencialmente. [...] Tal foto, com efeito, jamais se distingue do seu referente (do que ela representa), ou pelo menos não se distingue dele de imediato ou para todo o mundo [...] a Foto- grafia tem algo de tautológico: um cachimbo, nela, é sempre um cachimbo, intransigentemente. [...] Seja o que for o que ela dê a ver e qualquer que seja a maneira, uma foto é sempre invisível: não é ela que vemos.}

Tal constatação, que impede a Fotografia de ter aquilo a que Barthes denomina de "dignidade de uma língua" (Barthes, 1984, p.16), delimita o universo de problemáticas aqui exploradas, por um lado, pela especificidade acima referida da fotografia e, por outro, mais desenvolvido por Flusser, pela perspectiva técnica.

Flusser faz a distinção das duas modalidades - pictórica e "técnica" - de representação imagética nos seguintes termos:

No caso das imagens tradicionais, é fácil verificar que se trata de símbolos: há um agente humano (pintor, desenhista) que se coloca entre elas e seu significado. Este agente humano elabora símbolos "em sua cabeça", transfere-os para a mão munida de pincel, e de lá, para a superfície da imagem. A codificação se processa "na cabeça" do agente humano, e quem se propõe a decifrar a imagem deve saber o que se passou em tal "cabeça". No caso das imagens técnicas, a situação é menos evidente. Por certo, há também um fator que se interpõe (entre elas e seu significado): um aparelho, e um agente humano que o manipula (fotógrafo, cinegrafista) (2002, p.15).

\section{Poderíamos entender o encontro da imagem cinematográfica com a imagem pictórica, no momento em que a primeira capta a segunda, e a segunda aparece na primeira, como uma medição ou uma junção de forças de modalidades do modo de representação imagético.}

Evidentemente, o que está posto é que quando mudam os instrumentos de produção de uma imagem, as possibilidades de representação do referente conseqüentemente se apuram em termos de "fidelidade". As possibilidades técnicas, portanto, passam a oferecer mecanismos para que a produção desta imagem permita que ela seja o mais próximo possível (em termos de conter indícios do referente) daquilo que quer representar. A evolução destas possibilidades teve no cinema seu ápice: mais do que representar indicialmente o referente de maneira estática como a fotografia, a cinematografia criou a sensação de movimento para estas imagens colocadas e exibidas em seqüência.

Ainda que autores como Arheim demonstrem toda a impossibilidade de considerarmos o cinema simplesmente como reprodução da realidade ${ }^{4}$, não há como negar ser o produto que alcançou mais fidelidade, dentre os modos de representação imagética, em termos de referência ao representado. Operação que lhe proporciona, por exemplo, ser um substituto da pintura quando esta tinha a função, entre outras, de representar em termos de testemunho uma cena.

Bernadet, como que para justificar a frase de Godard por ele mesmo citada - "A fotografia é verdade. O cinema é verdade 24 vezes por segundo" - invoca um momento pouco anterior ao cinema, demonstrando o contexto em que a possibilidade de reprodução da realidade 
o mais "fielmente" possível (em termos de indicialidade ao referente representado) era socialmente aguardado.

É bastante simples provar que a burguesia sempre procurou elaborar uma estética que apresentasse as obras como expressão do real. Uma prova entre mil outras possíveis são as publicidades de divertimentos populares que Vicente de Paula Araújo levantou nos jornais do Rio numa época anterior ao cinema. Em alguns parques de diversões, apresentavam-se pinturas circulares de $180^{\circ}$ ou $360^{\circ}$, os chamados panoramas. De um deles, representando a "Entrada da Esquadra", dizia a publicidade: "O efeito extraordinário dessa pintura produz no espectador a mesma impressão da realidade, como se o observador estivesse no lugar verdadeiro". De outro sobre a "Descoberta do Brasil": "oferece ao visitante a sensação igual à que poderia ter observando o fato verdadeiro". A respeito de uma fotografia exposta publicamente mostrando o Mosteiro de São Bento: "reproduzido com tal fidelidade, precisão e minuciosidade que bem se via que a coisa tinha sido feita pela própria mão da natureza e quase sem intervenção do artista". Estas frases indicam claramente o quanto se ansiava por espetáculos que pudessem ser oferecidos como reprodução do real, e o cinema veio a calhar para se encaixar nesta linha e para reforçá-la. (1985, p.21)

Se o cinema é o ápice do emprego da técnica com este intuito, não é de forma diferente que podemos nos referir à produção de imagens no Quattrocento. Francastel vai lembrar duas invenções (ou descobertas) atribuídas à época do Renascimento que transformavam a pintura na mais perfeita técnica de reprodução da realidade: a pintura a óleo e a perspectiva ${ }^{5}$. Baxandall, entretanto, lembra um detalhe evidente, mas elementar: "em primeiro lugar, compreender o quadro supõe que possamos identificar uma certa convenção representacional, base-

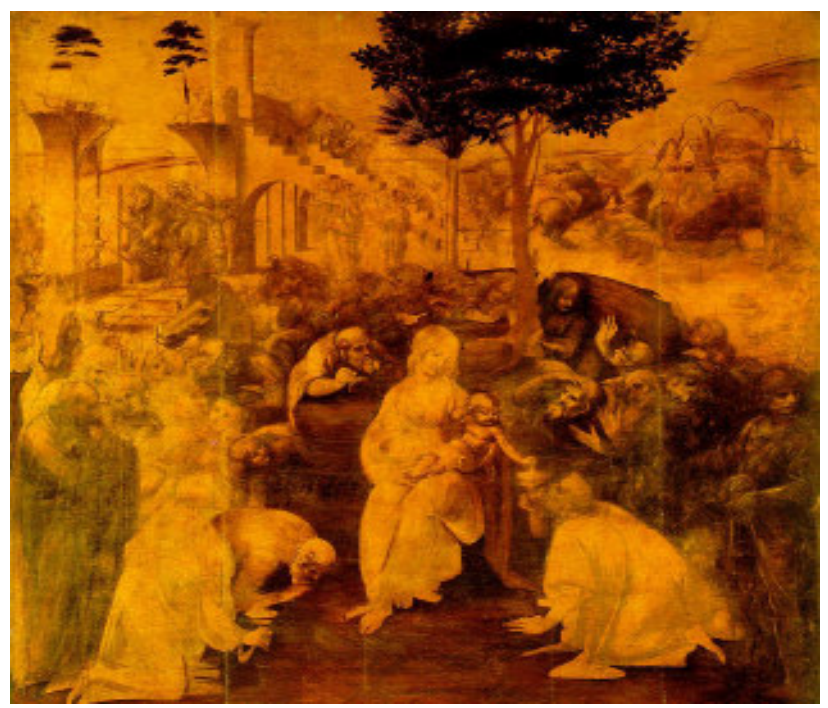

ada no fato de o pintor estar empregando cores sobre um plano bidimensional para se referir a algo que é tridimensional: é preciso que se entre no espírito do jogo [...]" (1991, p.40) ${ }^{6}$, no que invoca, de fundo, a própria idéia de Leonardo da impossibilidade de uma pintura parecer ter o mesmo relevo que o modelo natural.

Se o cinema e a pintura, dados os seus contextos, são produzidos para praticamente o mesmo fim (vide citação anterior, em que Machado assinala a filiação funcional objetiva da fotografia - base do cinema - à pintura renascentista), podemos perceber que o emprego da palavra "técnica", enquanto um conjunto de processos e atividades utilizados (manejados) para obter certo resultado - neste caso, uma imagem representativa - serve a ambos. Quando Flusser menciona "imagens técnicas", mais do que estar referindo especificamente as possibilidades técnicas mecânicas, elétricas e eletrônicas que passam a estar em jogo, aponta para todo o manancial de possibilidades que esta técnica abre para a produção e o uso destas imagens.

Da excelência do modo de representação imagético pictórico que é a pintura à excelência do modo de representação imagético técnico que é o cinema, permanece, entre outras, uma mesma possibilidade: dar a ver a algo através de uma sua representação sígnica; e modificamse as características da técnica nisso empregadas. $\mathrm{O}$ encontro destes dois momentos de apuro do modo de representação imagético - a imagem cinematográfica de Tarkovski quando filma a imagem pictórica de da Vinci; e a imagem pictórica de da Vinci quando aparece na imagem cinematográfica de Tarkovski - pode ajudar a compreender o que fica de um para o outro, e o que pode nos oferecer para compreender a força que a imagem possui em uma de suas funções que é a de representar, com o objetivo da maior fidelidade possível, o seu referente.

\section{Tarkovski $x$ da Vinci}

Quando Andrei Tarkovski deixa sua câmera fixa por quatro minutos filmando uma parte da pintura A Adoração dos magos, de Leonardo da Vinci, e coloca a seqüência de fotogramas daí resultante como abertura de seu filme $O$ Sacrifício, parece estar apontando para questões como essas. Poderíamos entender o encontro da imagem cinematográfica com a imagem pictórica, no momento em que a primeira capta a segunda, e a segunda aparece na primeira, como uma "medição" ou uma "junção" de forças de modalidades do modo de representação imagético. Para além do que significa na trama do filme, talvez pudéssemos entender o encontro promovido por Tarkovski um elogio a este modo de representação, momento no qual as questões acima abordadas

Figura 1: A adoração dos magos, 1481/

1482, Leonardo da Vinci

Óleo sobre madeira, 243 X $246 \mathrm{~cm}$, Galleria

delli Uffizi, Florença, Itália 
estariam implicitamente explícitas. As considerações do diretor sobre imagem, e sobre da Vinci, indicariam esta direção.

Para Tarkovski "é difícil que um conceito de imagem artística possa ser expresso através de uma tese precisa, fácil de formular e de compreender" (2002, p.122). A imagem artística, para ele (pois é nesta característica que usa o termo imagem, ainda que esteja falando do modo de representação imagético indicial, e não de uma imagem abstrata artística, por exemplo) é uma impressão de verdade: está nela a possibilidade de expressão da própria vida - "[...] a imagem não é certo significado expressado pelo diretor, mas um mundo inteiro refletido como que numa gota d'água" (2002, p.130), ou seja, "ela não designa nem simboliza a vida, mas a corporifica, exprimindo-lhe o caráter único" (ibidem, p.131).

Figura 2: Fotograma do trecho onde ocorre o "encontro de imagens", no filme O Sacrifício, de Andrei Tarkovski, 1986, Suécia, 142min. (pedaço da pintura de da Vinci filmada pelo cinema de Tarkovski)

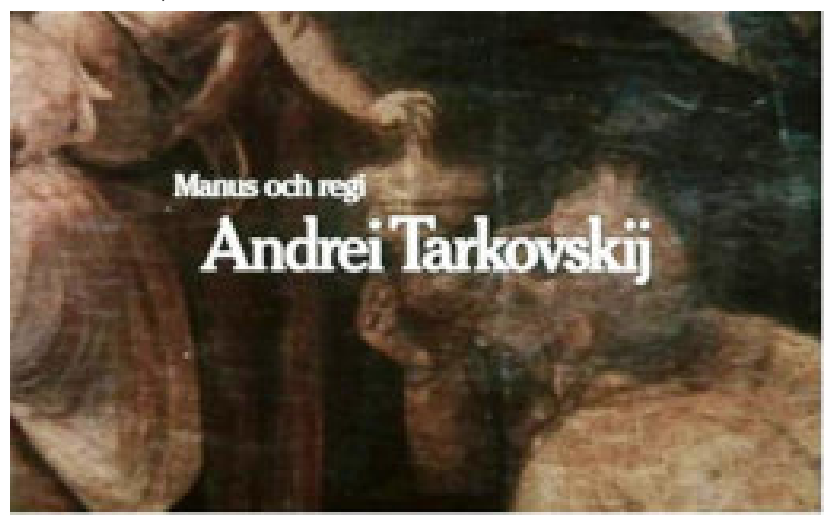

Suas considerações sobre Leonardo vão ao encontro das caracterizações que dá sobre a função da imagem. Para Tarkovski, da Vinci teria a extraordinária capacidade de "examinar o objeto de fora, do exterior, com um olhar que paira por cima do mundo" (Tarkovski, 2002, p.127), talvez como o olhar de uma câmera cinematográfica.

Ao colocar parte de uma obra de Leonardo na abertura de um filme de longa-metragem, algo que poderíamos depreender é que o diretor soviético estaria procurando associar o que caracteriza na imagem a função de exprimir um mundo inteiro em uma gota d'água, com a característica que confere a da Vinci de poder enxergar esta totalidade do mundo de fora dele. Se a imagem corporifica e exprime a unicidade da vida, Tarkovski faria isso duas vezes ao filmar da Vinci: uma pelo seu modo de representação imagético que é a imagem resultante da sua câmera (o cinema), e a outra pelo modo de representação imagético que mostra através da sua imagem cinematográfica: a pintura de da Vinci.

Ao fazer isso a partir do cinema, Tarkovski estaria promovendo um elogio das duas modalidades extremas do modo de representação imagético. Quando corta o quadro pintado por da Vinci e coloca os créditos sobre os fotogramas que representam a parte escolhida da pintura (figura 2), "obedece" (no sentido de utilizar) às possibilidades técnicas que o cinema oferece (a delimitação do campo, por exemplo); e ao permanecer mais de quatro minutos com a lente parada sobre o mesmo objeto - que não por acaso é um quadro de um ícone da pintura - "desobedece" (ou simplesmente não utiliza) às possibilidades de promover a idéia de movimento que a apresentação de fotogramas em seqüência (cinética) permitiria. Ao não se valer desta possibilidade técnica mecânica que caracteriza essencialmente o cinema, o cineasta, através dele - cinema -, refere explicitamente (ao mesmo tempo em que presta reverência a) a pintura. O que deixa o ato mais evidente é a pintura ser de Leonardo, depois de saber das considerações de Tarkovski a seu respeito: pelas possibilidades que a técnica do cinema permite de captar "de fora" uma realidade (na medida em que a testemunha, sobretudo), Tarkovski filma, estaticamente, parte da obra de um pintor ao qual ele confere justamente esta característica: portador de um olhar que paira sobre o mundo.

Se Tarkovski faz isso, o faz através de seu suporte cinema -, sobre o qual teria plena consciência das possibilidades. E se isso é verdade, há peculiaridades do suporte que inescapavelmente determinam a expressão do conteúdo que por ele é veiculado - ou Tarkovski não teria feito o que se acabou de se considerar que tenho feito, nem poderia ter percebido na pintura de da Vinci o que percebeu. Nesse sentido, é que deveríamos examinar até que ponto a técnica (ou o suporte) "influenciam" na imagem que comportam.

\section{Expressão, suportes e inter-relações}

Desta vez, é Machado quem é peremptório: “quando se fala de imagens, é impossível pensar a estética independentemente da intervenção da técnica" (1997, p.223). Ao se colocar clara e exclusivamente do lado da técnica, o autor parece rechaçar qualquer possibilidade de pensar o estatuto do modo de representação imagético ainda (ou além) independente do material que fará seu veículo.

Menos enfático, Aaron Ridley, ao comentar a teoria estética de Collingwood ${ }^{7}$, assinala a intrínseca relação entre a expressão e o meio utilizado para expressá-la. "Alguém pode expressar sua experiência em palavras ou gestos, alguém pode expressá-la em tinta, sons ou pedra. Mas é preciso expressá-la em algo" (1999, p.38). Algo que se torna fundamental quando Ridley diz que "assim, o ato de expressão está indissoluvelmente vinculado ao material no qual se realiza".

[...] se a expressão é necessariamente materializada, segue-se que essa exploração deve ser também uma exploração do próprio meio material de expressão. Para tomar o exemplo do próprio Collingwood: 
Cézanne explorou sua reação ao Monte Saint-Victoire - de fato, sua obsessão por ele - pintando-o repetidas vezes. Ele explorou sua obsessão valendo-se de sua pintura; mas explorou, igualmente, sua pintura, valendo-se de sua obsessão (1999, p.39).

Da afirmação de Ridley, podemos observar três pontos. O primeiro é o de que, assim como Machado, sua perspectiva em relação ao que nomeia expressão é a da materialidade: "se a expressão é necessariamente materializada" são suas palavras. Ambos os autores, portanto, não estão, a princípio, interessados no problema conceitual, seja de imagem, seja de expressão (e conseqüentemente, no de expressão - ou representação - imagética). O segundo é que, posicionando-se desde este ponto de vista - empírico - nem haveria como a materialidade não "influir" na expressão imagética. De modo que o terceiro ponto, assim sendo, é o de que a discussão já se inicia resolvida: a expressão (pela imagem) ou o modo de representação imagético, visto a partir de uma perspectiva da materialidade, natural, evidente, e necessariamente tem o resultado de sua expressão (ou de sua representação) dependente da técnica utilizada para tal.

Todavia, ainda que Machado seja definitivo ao afirmar que

[...] jamais se pode ignorar o papel determinante jogado pelas técnicas de produção na realização dos fenômenos estéticos sob pena de reduzir qualquer discussão estética a um delírio intelectualista completamente ignorante da realidade da experiência produtiva" (1997, p. 223).

\section{A diferença, em relação ao pictórico e ao técnico, é que de certa forma características como estas estão postas no uso da pintura como representação imagética.}

Poderíamos não negar, mas suspender o que nos é apresentado como evidente: a determinância da técnica sobre a expressão ou representação. Um dos dados a se levar em conta para isso é a observação de que Machado menciona o termo "estética" duas vezes ao referir-se a esta dependência do que chama de fenômeno estético em relação à técnica. No caso de Ridley, como recém assinalado em relação à necessidade material de uma expressão, o caso é o mesmo. Sabe-se que a experiência estética só pode acontecer empiricamente: os sentidos são condições sine qua non para que ela ocorra. Logo, não há, logicamente, possibilidade da técnica empregada na materialização do objeto originário da experiência estética (o próprio objeto estético) não determiná-lo.

No entanto, ao suspendermos esta idéia da evidente dependência, ao invés de a negarmos, a desconstruiremos, invertendo os pólos binários, a fim de tornar possível perceber a questão da representação (ou expressão) via imagens também de outro ponto de vista. Se observarmos que o próprio Machado menciona uma "essência" da imagem, podemos ter uma entrada para este ponto de vista concorrente.

Sua menção aparece quando faz as aproximações das produções de imagens renascentistas com as produções das imagens técnicas (fotográficas), ao dizer que o "empenho na direção de uma imagem cientificamente verossímil" por parte dos renascentistas seria a "própria essência do que agora estamos chamando de imagem técnica" (1997, p.225). Se essência é aquilo pelo que uma coisa ontologicamente se define, ficaria difícil negar que teríamos aí uma "ideia" de imagem, transcendente (ou ulterior) à técnica empregada para que ela se materialize. Desta identidade essencial (ainda que seja de função: reproduzir objetivamente o real) que surge ao Machado aproximar as modalidades de representações imagéticas pictóricas renascentistas e técnicas modernas (fotográficas, logo cinematográficas) é que também se torna possível pensar a imagem não apenas necessariamente associada irremediavelmente ao suporte em que se faz aparecer.

Deste modo, de maneira clara, declinamos simultaneamente tanto da perspectiva empírica, que leva em consideração o fenômeno estético - cuja natureza do meio técnico é princípio imprescindível -, quanto da perspectiva metafísica, na qual a natureza conceitual solicita primazia. Na irredutibilidade de uma imagem poder existir sem um suporte material, podemos querer tentar entender o que é "a imagem" que ocorre neste (por este) suporte, para além do meio técnico, ou seja, na semiose (Peirce, 1990). Isto implica reconhecer que o significado de uma imagem está, desde certo aspecto, em outra imagem que a representa e que se torna, por sua vez, uma imagem a ser ao infinito por outra representada.

No caso do encontro de imagens aqui referido, a semiose expressa rigorosamente um caminho diferente daquele trilhado por empiristas ou metafísicos: o de compreender o sentido da imagem - e de seus encontros nos múltiplos movimentos que as constituem. Assim, tanto O Sacrifício pode ser, em dada circunstância, o significado de Adoração dos Magos, quanto Adoração dos Magos - definitivamente transformada em termos de significado depois do seu encontro com o filme de Tarkovski - pode, invertendo a flecha do tempo, configurar-se como o significado do Sacrifício. O que está entre, antes e depois do encontro - a imagem propriamente dita, tal 
qual a definimos neste artigo - constitui-se no objeto privilegiado de uma teoria da comunicação.

\section{Então, as características de incompletude e indefinição seriam da técnica (pintura, fotografia, cinema) e não do conceito de representação imagética.}

Assim, poderíamos pensar por duas vias o caso de Tarkovski. A primeira, mais óbvia: de que ao explorar sua obsessão por Leonardo, o diretor tenha explorado simultaneamente seu (o) cinema. A segunda, mais propícia, talvez: a de que ao explorar uma modalidade de representação imagética, a pintura (através da arte de Leonardo), com outra, o cinema, mais do que explorá-los ao mesmo tempo (o que de certa forma já estaria evidente), estaria explorando a natureza de ambos - que não por acaso é comum -: a própria representação imagética, ou o próprio conceito de imagem.

\section{Considerações finais}

Se o conteúdo de incompletude e indefinição das imagens escolhidas para serem representadas por outro suporte imagético reforçam a própria característica de incompletude e indefinição do uso da imagem como modo de representação indicial, poderíamos dizer que esta incompletude e indefinição só ocorreria justamente porque é preciso uma técnica para materializá-la. Então, as características de incompletude e indefinição seriam da técnica (pintura, fotografia, cinema) e não do conceito de representação imagética.

A diferença, em relação ao pictórico e ao técnico, é que de certa forma características como estas estão postas no uso da pintura como representação imagética, vide as afirmações de Baxandall de que é preciso "entrar no jogo" do pintor - o que afirma baseado já nas concepções do próprio Leonardo. No caso da imagem técnica, em função da possibilidade da indicialidade: do "reflexo direto do mundo", como afirma Santaella (2007, p.19), e do "efeito de real" que a tecnologia aí empregada possibilita, as características de incompletude e indefinição advindas da técnica utilizada para a reprodução imagética tenderiam a passar despercebidas. A confiança, portanto, nestas imagens (técnicas), citada por Flusser, teria origem no momento que em estes "defeitos" oriundos da técnica (incompletude e indefinição), fossem esquecidos. Neste sentido é que as imagens poderiam ser vistas ideologicamente como janelas (Flusser).

No caso de Tarkovski, é do simultâneo duplo trabalho por ele operado - explorar duas modalidades do modo imagético de representação: uma através da outra - que poderíamos inferir da sua produção uma tentativa de decifração da imagem ela própria. Ao fazer valerem-se um do outro - imagem pictórica e imagem cinematográfica - para expressar essa força, exporia suas vísceras: aquilo por onde (ou por que) sua força de representação acontece. A força no ato de representar a realidade que ela tem seria o que Tarkovski estaria tentando fazer emergir.

No fim (ou no começo), poderíamos dizer que o diretor se vale das duas técnicas para, por elas, e a despeito delas, legitimar a soberania da imagem na semiose. A arte de Tarkovski (ou a validade do encontro de imagens que promove) é que o elogio à representação imagética se dá a materialidade da técnica e ao conceito de imagem ao mesmo tempo. Ou seja, ele quer que se acredite na perfeição da imagem justamente pelos defeitos das técnicas que lhe transformam no soberano modo de representação mamecos

\section{NOTAS}

1 Na fase que abrange os diálogos Banquete, Fédon, Fedro e República, a filosofia platônica trata ontológica e epistemologicamente da teoria das idéias, em que uma das bases é a oposição entre o mundo sensível e o mundo ideal. Tema que o próprio filósofo passa a colocar em cheque a partir do diálogo seguinte; Parmênides. Na teoria das idéias, a tese básica platônica é a de que as coisas do mundo sensível são meras cópias imperfeitas dos originais ideais que existem no mundo das idéias; assim, os produtores de imagens, tais pintores e escultores, simbolizariam a própria prática desta impostura, ao tentarem reproduzir as coisas através das imagens que produziam.

2 O uso da palavra "técnica" é sempre problemático. Em relação à produção das imagens, Machado (1997, p.222) lembra que "Imagem técnica" seria toda a representação plástica enunciada por ou através de algum tipo de dispositivo técnico. Mas - e aqui começa a complicação - existirá alguma imagem, exceto aquelas que forjamos dentro de nós mesmos que não decorra da intervenção de um dispositivo técnico? Ao longo da história da arte, já nos defrontamos com técnicas pictóricas semi-artesanais estreitamente associadas à criação artística, como é o caso da gravura, da litografia, da serigrafia e de outros procedimentos do gênero. Seria o caso de nos perguntarmos também se o gesto em si da pintura dita artesanal não pressupõe já uma infinidade de mediações técnicas, desde a preparação das tintas e sua combinação, o tratamento da tela, o recurso a modelos matemáticos de representação (como é o caso da perspectiva renascentista) até a própria técnica de pintar, que pressupõe um aprendizado longo e difí- 
cil de modelos formais dados pela cultura em que se insere o pintor".

3 Sobre os três paradigmas da imagem, ver Santaella \& Nöth, (2002, p.159-187). Wim Wenders, na abertura do filme "Caderno de notas sobre roupas e cidades" (1989), afirma: "As imagens mudam muito rápido. E se multiplicam num ritmo infernal, desde a explosão que desencadeou as imagens eletrônicas - as mesmas imagens que agora estão substituindo a fotografia. Aprendemos a confiar na imagem fotográfica. Podemos confiar na eletrônica? No tempo da pintura, tudo era simples. O original era único e toda cópia era uma cópia, uma falsificação. Com a fotografia e o cinema, a coisa começou a se complicar. O original era um negativo. Sem uma amplificação, só existia o oposto. Cada cópia era o original. Mas agora, com a imagem eletrônica, e em breve a digital, não existe mais negativo nem positivo. A própria idéia de original ficou obsoleta. Tudo é cópia". Machado, sobre o que ocorre com a fotografia, e conseqüentemente com nossa relação com ela, afirma que "a tendência atual é encarar o registro fotográfico efetuado pela câmera como a mera obtenção de uma matéria prima que deverá ser posteriormente trabalhada e transformada por algoritmos de tratamento da imagem. "Fotografia" agora é o nome que se dá ao resultado de um processo de edição e não à marca deixada pela luz sobre uma superfície fotossensível" (1997, p.234).

4 Em "Fragmentos adaptados de Filme", de 1933, presente na coletânea 'A arte do cinema', de 1957, Arheim, ao argumentar em prol do cinema poder ser considerado arte, elenca uma série de questões para mostrar a impossibilidade de a imagem cinematográfica ser simplesmente uma reprodução mecânica da realidade. Entre elas, a impossibilidade da tridimensionalidade, a redução da profundidade, a delimitação da imagem e a distância do objeto. O ponto básico da argumentação é que a câmera não pode ser considerada como um olho, pois este está num corpo, e aquela não; logo, a captação da realidade é diferente de um em relação ao outro.

5 No texto Técnicas e Artes, do livro Imagem, visão e imaginação (1987), Pierre Francastel discute as relações recíprocas e relativas entre técnica e arte no Renascimento, chegando a uma conclusão, entre outras, que "as técnicas são possibilidades, produtos e usos; são meios e utensílios, enquanto que as artes são valores criados pela sociedade e que acabam, eles próprios, por criar sempre realidades, formas e objetos" (p.150).

6 Em O olhar renascente, a tese central de Baxandall, sobre as pinturas renascentistas é a de que fatores sociais característicos da época se transformavam em elementos identificáveis no estilo do pintor.

7 Escrita principalmente em Los principio del arte. Fondo de Cultura Econômica: México, 1960.

\section{REFERÊNCIAS}

ARHEIM, Rudolf. A arte do cinema. Lisboa: Edições 70, 1983.

ARISTOTELES. Metafisica. 2. ed. Coimbra: Atlântida, 1969.

BARTHES, Roland. A câmara clara. $6^{\text {a }}$ ed. Rio de Janeiro: Nova Fronteira, 1984.

BAXANDALL, Michael. O olhar renascente : pintura e experiência social. Rio de Janeiro: Paz e Terra, 1991.

BERNADET, Jean Claude. O que é cinema. 1.ed. São Paulo: Brasiliense, 1980.

CARLON, Mario. Imagen de arte/imagen de informacion: problemas actuales de la relacion entre el arte y los medios. Buenos Aires: Atuel, 1994.

FRANCASTEL, Pierre. Imagem, visão e imaginação. Lisboa: Edições 70, 1987.

FLUSSER, Vilém. Filosofia da caixa preta: ensaios para uma futura filosofia da fotografia. Rio de Janeiro: Relume Dumará, 2002.

MACHADO, Arlindo. Pré-cinemas \& pós-cinemas. São Paulo: Papirus, 1997.

SANTAELLA, Lucia. Por que as comunicações e as artes estão convergindo?. São Paulo: Paulus, 2005.

PEIRCE, Charles Sanders. Semiótica. São Paulo: Perspectiva, 1990.

TARKOVSKI, Andrei. Esculpir o tempo. São Paulo: Martins Fontes, 2002. 